\title{
Cryotherapy: Physiological Considerations and Applications to Physical Therapy
}

\author{
Anna Lubkowska \\ Department of Physiology, Faculty of Biology, Szczecin University, \\ Chair and Department of Biochemistry and Medical Chemistry, \\ Pomeranian Medical University, \\ Poland
}

\section{Introduction}

Contemporary cryogenics has been developing from the end of the 19th century since the liquefaction of oxygen, nitrogen, carbon dioxide and hydrogen, and also the industrial production and storage of liquid coolants, enabled the development of cryobiology and the use of extremely low temperatures in medicine. The term "cryotherapy" was first used in 1908 by A.W. Pusey to describe the treatment of skin lesions with very low temperatures [Zagrobelny et al. 1999; Jezierski 2006;]. Currently, cryotherapy refers to various treatments aimed at lowering the body surface temperature without tissue destruction, whereas in cryosurgery diseased tissues are destroyed through freezing. The world's first cryogenictemperature chamber was set up in Japan, in 1978. Thanks to Yamauchi and his team, cryotherapy began to be widely used in medicine [Zagrobelny 2003; Skrzek 2009].

The clinical application of low temperatures is recommended for inflammatory conditions, such as swelling and acute localised pain. It is essential to clarify the distinction and clear labelling of methods based on low temperature usage and the intended purpose, as the body's response to low temperature depends on the temperature, method of application, exposure time, method and rate of heat loss, humidity of the cooled air, and the characteristics and age of the subjects.

Cryostimulation requires making use of a suitable croyogenic liquid as a coolant source. It is based on the use of very low temperatures $\left(-100^{\circ} \mathrm{C}\right.$ and lower) in order to induce a physiological reaction to cold.

A different category of treatment in modern medicine and rehabilitation, the cooling of tissues, is based on different methods and rates of tissue heat loss using various temperatures and methods of application achieved by the use of bags of ice, frozen silicone gel, salt solution, wet cold (which is not tolerated well by many people), partial bathing in cold water or whole body bath (temperature below $10^{\circ} \mathrm{C}$ ). Cooling results in heat loss, the treated body area experiences vasoconstriction, a long-duration decrease in the temperature of the exposed tissues, decrease in inflammatory reaction and inhibition of strong symptoms of inflammatory reaction, but without any stimulatory effect [Rawecka \& Rokita, 2006]. 
Depending on the size of the body area to be treated with cryogenic temperatures, the following types of cryotherapy may be distinguished:

1. Local cryotherapy (involving a small body area): ventilation with nitrogen vapours (gas temperature at the outlet of the nozzle can range from $-160^{\circ} \mathrm{C}$ to $-196^{\circ} \mathrm{C}$ ), ventilation with a mixture of nitrogen vapours and cooled air (temperature of the gas mixture varies from $-100^{\circ} \mathrm{C}$ to $-178^{\circ} \mathrm{C}$ ), and ventilation with cold air (temperature ranges from $30^{\circ} \mathrm{C}$ to $\left.-34^{\circ} \mathrm{C}\right)$.

2. Whole-body cryotherapy (involving the entire body, including the head): cryosauna, two-stage chambers, cryochamber with cool retention effect; chambers cooled with a mixture of liquid nitrogen vapour and air, or with a compression cooling system. During low-temperature treatment in a chamber, the cold air cools the whole body.

After the first cryochamber in Japan (1978), another one was created in Germany in 1982, and the third in Wrocław, Poland, in 1989. At present a few dozen cryochambers may be found around the world. A growing number of centres conduct scientific research on the effects of whole body cryostimulation on the human body, yet knowledge on the subject is still lacking. While whole-body cryostimulation (WBC) is not harmful or detrimental to healthy subjects, the effects are being studied in relation to: 1 . Motor activity and physical efficiency; 2. Cardiovascular response; 3. Lipid profile; 4. Hematology; 5. Hormones; 6. Antioxidant Defense System; 7. Immunology and inflammation 8. Recovery from exerciseinduced muscle damage.

\section{Cryogenic liquids}

Cryogens (cryogenic liquids) are those liquids with a boiling point not exceeding $120 \mathrm{~K}$ under normal atmospheric pressure. The following are various types of cryogens and respective temperature ranges:

1. wet cold - water with ice, $0^{\circ} \mathrm{C}$

2. damp cold - cold air, temperature from $-15^{\circ} \mathrm{C}$ to $-30^{\circ} \mathrm{C}$

3. dry cold- vapours of liquefied gases:

a. liquid nitrogen vapour: $-196^{\circ} \mathrm{C}$

b. carbon dioxide vapour: $-75^{\circ} \mathrm{C}$

The most rapid effect can be achieved with water (wet cold). Subjecting a patient to a cold bath, however, is unpleasant and can cause shock, and therefore is used only in selected cases. Cryostimulation using dry cold (vapours of liquefied gases: nitrogen, air, carbon dioxide) is also quick, convenient and much more patient-friendly [Bojek 2006; Rawecka \& Rokita 2006].

Cryogenic liquids, vapours and cold gases used in the wrong way are able to cause serious damage related to frostbite. However, liquid nitrogen in short contact is not harmful, because at the time of contact with warm tissue, it evaporates intensely. It is important to avoid contact with the eyeball as it may cause serious and irreversible damage to the cornea. The danger with these substances is in their low temperature and high density. They are kept in specially insulated containers that are designed to withstand rapid temperature changes. 


\section{Cryostimulation procedures}

Whole-body cryotherapy is often used as preparation of the patient to physiotherapy. However, cryotherapy is also increasingly often performed for the purposes of biological regeneration and prevention of musculoskeletal overload and injury (athletes), and as a way of increasing immunity. In some cases with symptoms of inflammation (acute and chronic musculoskeletal injuries), the purpose of cryostimulation is to decrease the temperature of the inflamed tissue as cold is known to limit inflammation symptoms. This protects against oedema of periarticular tissues and any further damage caused by pressure and movement of tissues. In such cases very good results are obtained by local cryotherapy.

\subsection{Local cryostimulation}

Local cryotherapy treatment uses usually the following cryogens: liquid nitrogen, carbon dioxide, cooled air [Sieron \& Cieslar 2003]. Prior to cryostimulation, the patient should thoroughly dry the body surface to be subjected to treatment. It is most desirable to keep the patient in a standing position or if not possible, in a sitting or lying position. Procedure duration is defined individually for each patient, depending also on the body structure, muscle mass and fat thickness. Cryotherapy is not used for more than about 5 joints at the same time which should not be longer than 12-15 minutes. The hand, foot and spine are considered as a single set of small joints [Księżopolska - Pietrzak 1998].

The treatment time takes usually from $30 \mathrm{sec}$ to several minutes (3-4 min), depending on the patient's skin response. The treatment may be repeated twice a day but with a break of at least 6 hours. The recommended duration of the break is determined by the sustained stimulatory effect after a single session. In children, treatment should be used very cautiously and of a shorter duration than adults due to the higher sensitivity of the younger skin and usually lower amount of subcutaneous fat. The distance of a cryoapplicator from the surface of the body depends on the quality of the device, and the temperature obtained at the nozzle exit, usually about $10 \mathrm{~cm}$ from the body surface (in older devices, the distance can be up to $15 \mathrm{~cm}$ ). The treatment area of the body should be progressively swept over to avoid cooling of just one spot. Initially the patients experience a burning sensation. The patient must stay in communication with the physiotherapist and inform him about the pain or the burning sensation. After reported discomfort the applicator should be positioned further from the tissue, or the movement of the nozzle should be sped up. Rapid skin blanching is an indicator for immediate cessation of the treatment [Jezierski 2006].

During cryotherapy, one must remember about the bi-phasic vascular response to extremely low temperatures, and bear in mind the desired effect. Initially, in micro-circulation, a constriction of vessels as a result of closing of pre-capillary sphincter and activation of arteriovenous anastomoses, which takes from a few to a ten or so seconds, after which the vessels dilate and arteriovenous anastomoses close, during which blood flow increases. A lower temperature of the coolant (liquid nitrogen vapour) results in a stronger and faster first stage, i.e. vasoconstriction causing tissue ischemia. In this way one can reduce the effects of trauma, reduce the rate of metabolic processes (which may be helpful for example in the physical therapy of arthritis), while hypoxia reduces perceived pain. In the second phase, local hyperaemia occurs (increase in local blood flow due to the effect of internal and external factors, known as the rebound effect), during which metabolic processes are intensified and muscle tension is reduced. 
Treatment duration and temperature are diverse and depend on whether the goal is mainly to generate secondary hyperaemia and reduce muscle tension, e.g. in preparing the patient for physiotherapy or massage, or whether the first phase is the primary goal, slowing metabolism and reducing the effects of trauma. Cryotherapy is often used as an analgesic agent, and this effect can last for several hours. The manner of cryostimulation is also influenced by the patient's age, physical condition, sensitivity to low temperature, or existing disease and its severity [Kasprzak \& Markowska 2008].

In some cases, excessive hyperaemia may worsen pain in the long-term (with a strong inflammatory component). In this case cold therapy instead of cryotherapy is recommended.

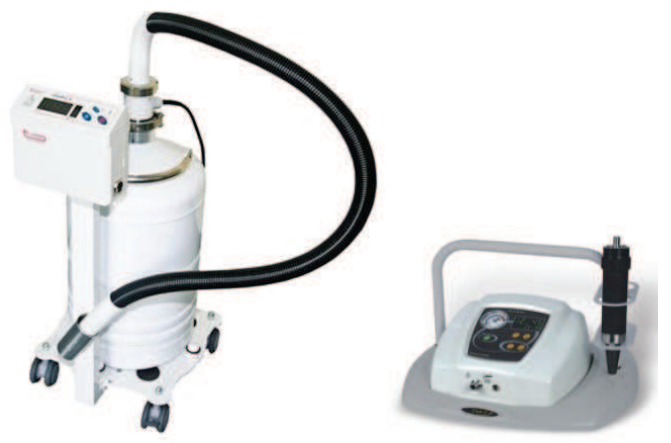

Fig. 1. Examples of stationary and portable cryotherapy apparatus

\subsubsection{Diseases in which local cryotherapy is used}

Patients with locomotor disorders are now the largest group of patients eligible for cryotherapy. An efficient muscle-joint and skeletal system is fundamental for the functioning of the human body. The inability to move affects an individual both socially as well as psycho-socially. As musculoskeletal disorders affect people of all ages and from all social groups, researchers worldwide have been looking for the most beneficial methods of treatment. Cryotherapy has gained the greatest recognition as supporting treatment of the motor system [Bieńkowska et al. 2006; Hopkins 2006; Łuczak \& Michalik 2006].

\section{Ankylosing spondylitis}

In ankylosing spondylitis pain forces patients to reduce their motor activity. The progress of the disease and reduced physical activity leads to a reduction in joint mobility, periarticular ossification and degenerative changes. The spine assumes deep thoracic kyphosis, deep compensatory cervical lordosis, thoracic stiffness and stiffness in the peripheral joints affected by inflammation. The advancing total thoracic rigidity causes a situation where lung ventilation only takes place through diaphragm movement. Kinesitherapy and cryotherapy are currently the preferred treatments for ankylosing spondylitis. Cryostimulation decreases the concentration of acute phase proteins and immunoglobulins in serum and increases the concentration of $\beta$-endorphin.

The cryotherapy-induced reduction of inflammation and the higher threshold of pain perception allows the use of physiotherapy to a greater degree. The patient benefits from a 
reduced need for analgesics and anti-inflammatory drugs. Local cryostimulation should be followed by kinesitherapy based on an individual program, allowing for the period of the disease (acute or remission), the severity of the disease, its extensiveness, the patient's age and the incidence of other diseases. In the acute phase of the disease, cryostimulation plays an important role in reducing pain as well as inflammation, allowing for sufficient activity of the patient during exercises. During remission, the most important aim is to gradually regain motor functionality [Sieron \& Cieslar 2003; Jezierski 2007].

\section{Rheumatoid arthritis (RA)}

RA is a chronic immunologically dependent connective tissue disease that is characterised by non-specific, symmetric arthritis, sometimes accompanied by non-joint changes and systemic complications. The course of RA is characterised by alternating periods of joint inflammation and remissions. This disease can occur in three forms: mild, medium and acute. Diagnosing the disease is synonymous with pharmacological treatment that should be supported by physical therapy. Cryostimulation has beneficial effects in RA - it increases active muscle power and lowers passive muscle power. Pain and increased oedema of joints is reduced, resulting in increased range of motion in the inflamed joints. A single cryostimulation of a specific part of the body takes about 3 minutes and has both analgesic and anti-inflammatory effects. Therefore cryostimulation should be immediately followed by physical exercise [Sieroń \& Cieslar 2003; Straburzyńska - Lupa et al. 2005; Krawczyk Wasilewska et al. 2007; Jezierski 2007].

\section{Osteoarthritis (OA)}

Symptoms of osteoarthritis include morphological, biochemical, molecular and biochemical changes in cells of the cartilage, which lead to softening, fibromatosis, ulcers and weight loss of articular cartilage, sclerosis and thickening of bone, osteophytes and subchondral cysts. Patients with hip degeneration experience destruction of cartilage and subchondral bone, and pain in the hip. Local cryostimulation aims at maximum cooling of the hip. Cold should be applied from the front and medially to the groin and the space between the pubic symphysis and thigh adductor and from the back to the gluteal fold and ischial tuberosity. In addition, cryostimulation should involve the entire thigh, gluteus maximus and iliopsoas. The duration of treatment ranges from 3 to 6 minutes. In degeneration of the knee, cryostimulation is performed on the knee joint and thigh muscles. Cooling of the joint is done best in a sitting position with a bent knee (cold should be first applied on sides, then around the knee cap). Osteoarthritis may involve the joints of the spine or vertebral stem. Cryostimulation is performed on a relevant segment of the spine area and muscles situated in the area. The procedure is followed by exercises intended to strengthen back muscles and abdominal muscles, stretching and increasing the mobility of the spine exercises, and correction exercises [Sieroń \& Cieslar 2003; Jezierski 2008; Pasek et al. 2009].

\section{Shoulder impingement syndrome}

Treatment of shoulder impingement syndrome is not straightforward. Pharmacological methods are often accompanied by physiotherapy and anti-inflammatory analgesic electrotherapy, ultrasound, massage, kinetic therapy and increasingly popular cryotherapy. The aim of physiotherapy treatment is improvement in the functional efficiency of the limb through the elimination or reduction of pain. Literature reports describe both cold therapy, resulting in a slowdown of inflammatory reactions and reduced metabolism in cooled tissues, and cryostimulation which aims at improving conditions in blood circulation in a 
given area and to exert a strong analgesic effect. Cryostimulation for patients with shoulder impingement syndrome increases the range of motion in the transverse plane, bending and movement of external rotation, and a slight effect on straightening and bending in the sagittal plane, abduction and internal rotation [Sieron \& Cieslar 2003; Lisinski et al. 2005; Boerner et al. 2007].

\section{Gouty diathesis}

This inflammation of joints is caused by crystallisation of sodium urate in synovial fluid and crystal deposition in tissues. Another form of this disease is chondrocalcinosis caused by calcium pyrophosphate dihydrate crystallisation in synovial fluid and crystal deposition in articular cartilage. In patients with acute gout, cryostimulation can be applied only after the attacks. Local cryotherapy causes a short-term reduction in the intensity of local inflammation, but does not stop an attack of gout. Kinesitherapy is introduced gradually and with caution, due to the persistent deposits of sharp crystals in cartilage and other connective tissues [Sieroń \& Cieslar 2003; Jezierski 2008].

\section{Osteoporosis}

This is a bone disease with a gradual decrease in bone mass with muscles and ligaments losing elasticity, and resistance to physical effort. The decline in mechanical bone strength is accompanied by degenerative changes. The disease affects the neuromuscular system and motor pattern, and results in the painful overload of muscles, ligaments, bones and joints. Treatment with cold, as in previous cases, leads to a reduction in pain, relaxes skeletal muscles and improves their strength, and increases range of motion within the treated joints [Księżopolska - Pietrzak 1998].

\section{Spinal pain syndromes}

These syndromes represent a serious medical problem as they affect between $60 \%$ to $90 \%$ of the European population. The lumbosacral spine is most affected, due to the sedentary lifestyle. Chronic pain leads to lower psychophysical performance. Cryotherapy decreases muscle tension and reduces the speed of nerve conduction, which are beneficial in relieving pain and allows further treatment with physiotherapy [Woźny et al. 2006].

\subsection{Whole-body cryotherapy}

This cryotherapy involves rapid cooling of the whole body at extremely low temperatures (cryogenic, below $-100^{\circ} \mathrm{C}$ ) to trigger physiological responses to cold. Such cryotherapy is performed in a cryogenic chamber, ensuring appropriate treatment conditions - temperature and humidity. While in the chamber, the patient must have regular contact with the physiotherapist, usually through glass doors and speakers. A special alarm device allows the patient to call for help in an emergency, and the door can be easily opened by the person inside. The inside of the chamber is lined with a material that does not absorb moisture. The walls do not have any sharp protruding metal parts to avoid contact with the patient, or to cause very unpleasant feelings [Biały et al. 1998; Adamowicz 2005; Brojek \& Warzocha 2006].

\subsubsection{Types of cryogenic chambers}

There are many types of chambers available in the market, and the choice depends on the design of the chamber, one room or two, the number of persons undergoing treatment at the 
same time, type of coolant. The choice of chamber is often also related to economic considerations.

\section{Two-stage cryogenic chamber}

This type of chamber consists of one or two vestibules where the temperature is approximately $-60^{\circ} \mathrm{C}$, and a main chamber in which the temperature is maintained within the range $-110^{\circ} \mathrm{C}$ to $-160^{\circ} \mathrm{C}$ (depending on the coolant). In order to maintain such a sufficiently low temperature, liquid nitrogen is pumped directly into heat exchangers which consist of 3 systems: cooling, air preparation and control. Maintaining the temperature is possible by heat exchangers installed in the vestibule and the chamber proper. Compressor, filters and dryer constitute the system of breathing air preparation. By this arrangement it is possible to introduce purified dry air, reducing the feeling of cold, and ensuring transparency in the chamber. The control system consists of a power supply and control cabinet, controller and computer, providing the desired data parameters. Extra security is provided by a glazed door, opening under the pressure of the body and an alarm button. A chamber of this type may be used by 5 people at one time [Cholewka \& Drzazga 2005].

\section{Cryochamber with cool retention effect}

This chamber is cooled with a mixture of liquid nitrogen and liquid oxygen in the proportions of atmospheric air. The air is pumped from the external tank and sprayed by specially prepared nozzles. This design is based on the phenomenon of cold retention in a basin, which reduces the importance of thermal insulation and elimination of the vestibule, reducing the cost of materials. Three to four people may stay in this cryochamber at the same time, although there is restricted access to wheelchair users. This type of a cryochamber may be without a vestibule, or with one or two vestibules [Cholewka \& Drzazga 2005].

\section{Cryobarrel (cryosauna)}

This is a cabin for one person. The patient is immersed in the cold vapours up to the arms, breathing air from the room with the head is located outside the reach of extremely low temperatures. It has a swinging door which opens under the pressure of the body, and contact with the patient is very good. Liquid nitrogen or liquid air is used to generate the coolant. The cryosauna has many advantage: low cost of use, good contact with the patient, easy assembly. It is contentious whether omission of the head is an effective treatment (with the head having a significant number of cold receptors), but it allows the use of cryostimulation by a person suffering from claustrophobia [Księżopolska-Pietrzak 1998].

\section{Cryochamber with a compressor cooling system}

This chamber with a compressor system uses air as a coolant. The chamber consists of two vestibules with a temperature of $-10^{\circ} \mathrm{C}$ and $-60^{\circ} \mathrm{C}$, and the chamber proper with a temperature of about $-100^{\circ} \mathrm{C}$. It can be mounted either indoors or outdoors (the chamber is isolated from the ground). Suitable temperatures in the inside are provided by three compressors, and the cooling system uses only non-combustible and non-toxic gases. This type of chamber has all the elements necessary for the safe performance of cryostimulation additional emergency exit, visual and audio contact with the operator. All parameters are monitored by a computer. The chamber can be used in group therapy [Migaj 2005]. 


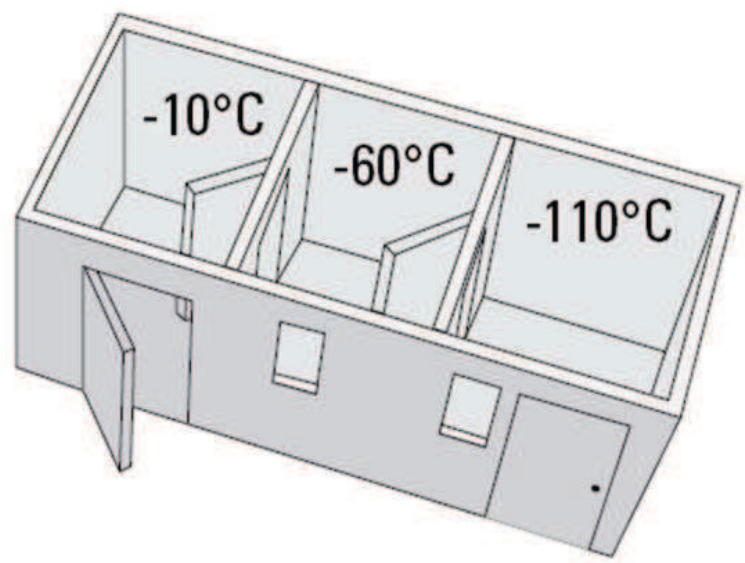

Fig. 2. The schema of crychamber with two vestibules (Zimmer MedizinSysteme GmbH, Germany)

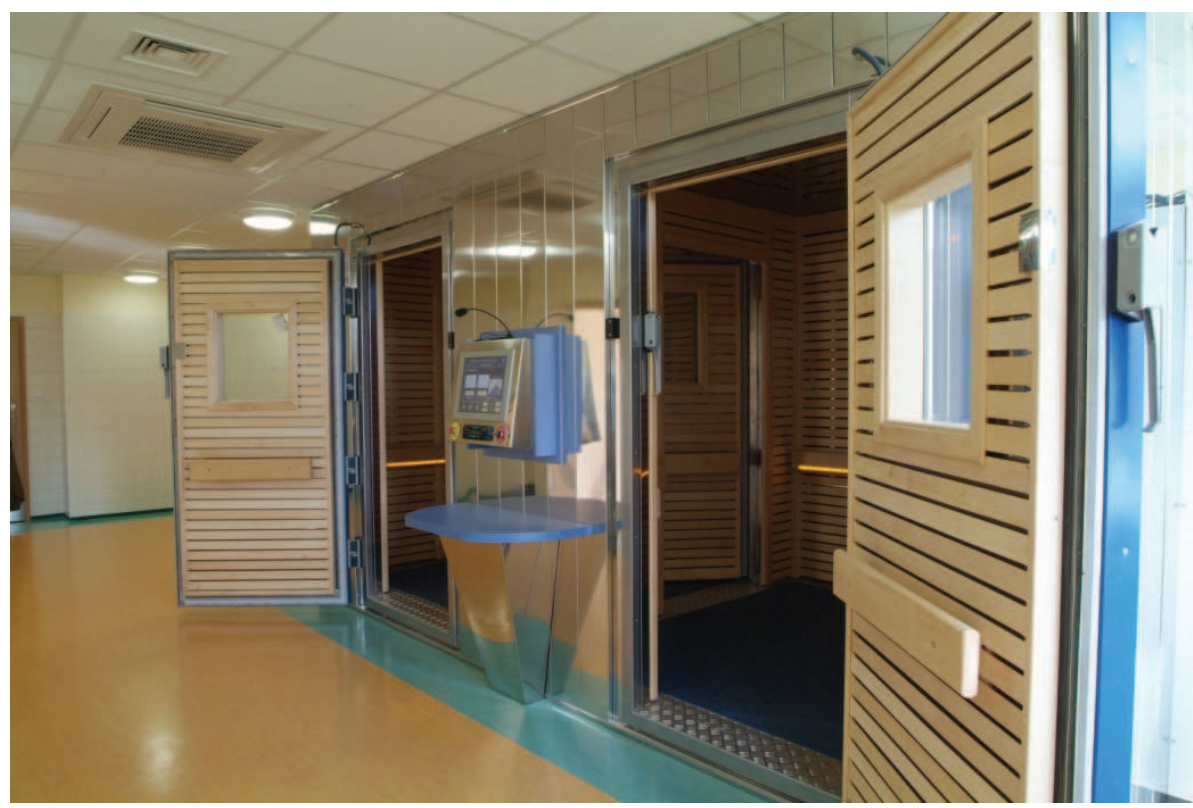

Fig. 3. Two stage cryochamber (CREATOR Sp. z o.o., Poland) 


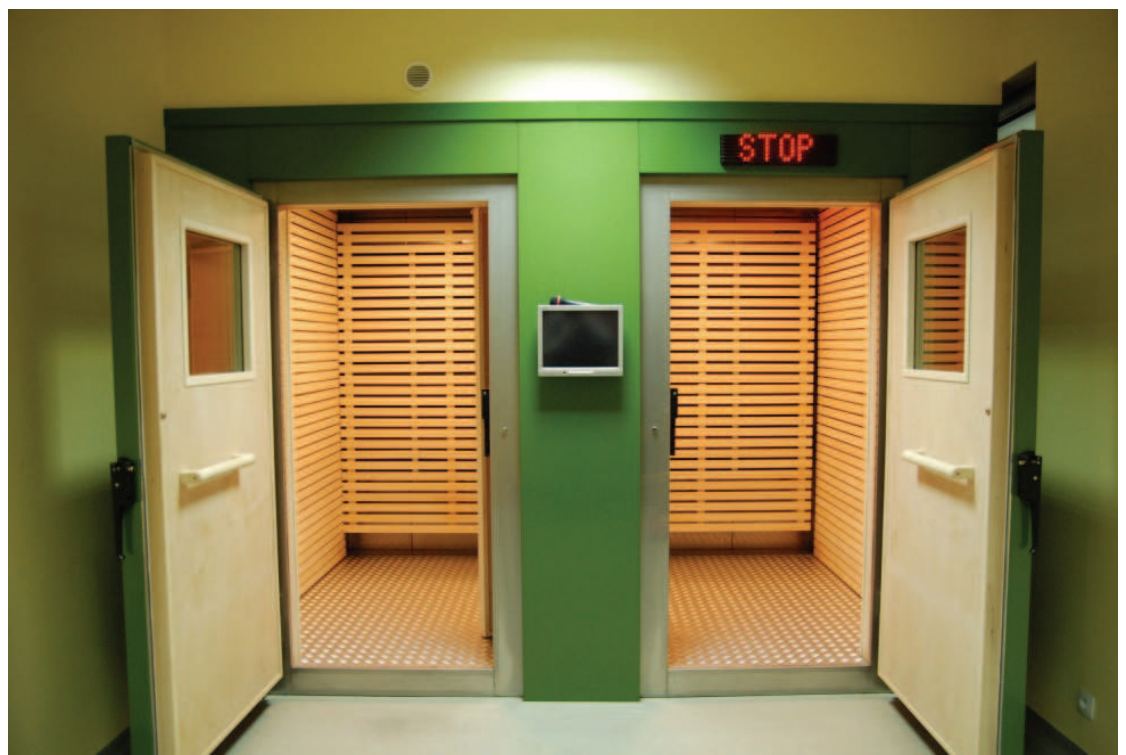

Fig. 4. Two stage cryochamber (KRIOSYSTEM Sp. z o.o. Poland)

\subsubsection{Preparation of patients for whole-body cryostimulation}

Patients who are eligible for treatment in a cryogenic chamber must undergo medical examination prior to treatment. An interview is carried out with each patient in order to detect any contraindications to cryostimulation, including questions relating to cold tolerance of the body. In all of the candidates for cryostimulation, blood pressure and heart rate are measured [Zagrobelny 2003].

In practice, whole-body cryostimulation is not permitted for patients with cardiac disease or unstable blood pressure. In Finland, cryostimulation is recommended only for people with a blood pressure below 160/100 $\mathrm{mmHg}$ [Westerlund et al. 2004] and in Poland usually below 150/90 mmHg [Lubkowska \& Szygula 2010; Lubkowska \& Suska 2011].

Bathing before cryostimulation is not recommended, and prior to entering the cryogenic chamber the patient should be wiped completely with a towel to remove sweat - drops of sweat left on the skin could turn into ice crystals, which causes a painful and unpleasant sensation of cold. Additionally, all the patients are informed of the necessity of slow and shallow breathing while in the cryochamber. Clothes during the treatment should cover those areas of the body which are most vulnerable to frostbite. These are primarily the hands, feet, outer ears and popliteal pits.

Taking into account protection of the external ear against frostbite, it is recommended to use earmuffs or a headband instead of a hat. Hands should be protected by gloves, which should be turned inside out to dry after use in the chamber. Undried gloves may cause frostbite in the fingers during subsequent treatments. It should also be remembered that a surgical mask lined with a layer of swabs is put on the face just before entering the chamber, as waiting in this mask may cause the accumulation of moisture in the mask [Brojek \& 
Warzocha 2006]. The mask is necessary for the protection of the lungs - if the extremely cold air reaches lung tissues in greater amounts, then after heating in the lungs its volume may even double which may result in respiratory oppression [Zagrobelny 2003].

The distribution of temperatures in the cryochamber results in the coldest air being located in the lowest area of the device, therefore clogs are the most suitable shoes during cryostimulation. A thick sole is good isolation of the feet from the ground. Socks should be short and protect only the area of the ankles and feet. The popliteal pit is very vulnerable to surface frostbite, as it has a tendency for intense sweating which may be prevented by instructing the patient to avoid sitting or putting a leg on a leg. It is best to wait for the treatment in the standing position, and wipe the area of the popliteal pit and put a knee pad on immediately before entering the chamber [Brojek \& Warzocha 2006].

Clothes used during cryostimulation should be made solely from natural components, such as wool or cotton, and should ensure full psychological comfort. It is best if pants are short and tight. Loose pants, such as boxers results in unpleasant rubbing of the frozen material against the body. Wearing any type of shirt is pointless as it inhibits the process of heat exchange during cryostimulation [Raczkowski \& 2007].

\subsubsection{Procedure of whole body cryostimulation}

Duration and temperature of cryostimulation are established for each patient individually before each entry to the cryogenic chamber. Usually, when the patient enters the chamber for the first time, the treatment starts with a 1 minute exposure, gradually extending in duration for subsequent sessions to $2.5-3$ minutes. Prepared patients are let into the vestibule by the operator where short-term adaptation to the low temperature occurs. The participants then move into the chamber proper.

Time of stay in the vestibule is not fixed, but usually it is associated with the time required to close the external door and open the door to the chamber proper. It is thus short, about 30 secs. During the entire session, the intensity of movement is limited to only a slow walk in order to eliminated the effect of skeletal muscle activity on the dynamics of cooling and heating of the body. In the middle of the session, the direction of movement is reversed. Contact with other people and the walls of the chamber should be avoided. During the entire stay in the chamber proper, patients should remain in eye and voice contact with the operators outside the cryochamber.

The staff at the site should include the physician that qualified the patients to the treatment, and a physician that could react in an emergency. After leaving the cryochamber proper, patients move to a place at room temperature. Usually kinesitherapy is applied after cryostimulation, usually for 20 to 30 minutes. It sometimes happens that after leaving the chamber patients do not perform any exercises. Undesirable effects that may occur after the session are shallow and quickly receding frostbites, usually in the legs [Suszko 2003; Zagrobelny 2003].

\section{Indication and contraindication for cryostimulation}

In clinical practice cryostimulation is used primarily in sports medicine. Professional athletes and healthy patients use cryostimulation for athletic recovery associated with a desirable effect for defensive and protective mechanisms in the human body. 
In the case of ill patients, cryotherapy is used in the following diseases:

- inflammatory musculoskeletal disease: rheumatoid arthritis, ankylosing spondylitis, rheumatic fever

- degenerative diseases and secondary degenerative changes in peripheral joints and the spine

- $\quad$ joint disease of metabolic origin such as gout

- mixed connective tissue disease

- $\quad$ rheumatic and soft tissue disorders (polymyositis and dermatomyositis)

- periarticular, tendon and joint capsule inflammation

- $\quad$ some skin diseases involving joints: psoriatic arthritis

- $\quad$ autoimmune diseases

- post-traumatic changes or overload of joints and soft tissues

- chronic inflammation of the cervical spine

- discopathies

- osteoporosis

- muscle overload

- neurological disorders (spastic paresis, multiple sclerosis, radicular neuralgia)

- depression syndromes, vegetative neurosis

The treatments in cryochambers are usually well tolerated by patients and complications related with the treatment are very rare. However, one must not neglect states in which the effect of low temperatures can be adverse for the patient. In qualifying patients for cryochamber treatment, one should pay attention to the following:

- patient's age

- $\quad$ the existing diseases

- nutrition

- performance of vascular vessels

- duration of cold and its intensity

- intaken drugs

- consumption of alcoholic beverages

- individual characteristics of response to cold

All these factors determine the suitability of using cryogenic treatment or can disqualify patients. Additionally, qualification to cryostimulation should be based on the results of basic spirometric and cardiological tests.

The following contraindications are known for the application of cryogenic treatment:

absolute contraindications to cryostimulation

- cold intolerance

- cryoglobulinaemia

- cryofibrinogenemia

- Raynaud disease

- cold utricaria

- $\quad$ open wounds and ulcers

- gangrenous lesions

- $\quad$ thromboembolic changes and inflammation in the venous system 
- agammaglobulinemia

- central nervous system disease

- $\quad$ sympathetic neuropathy

- hypothyroidism

- local blood flow disturbances

- significant anaemia

- claustrophobia

- mental disorders, which may prevent adequate co-operation with the patient in the chamber

- emaciation and hypothermia

- cancer

- Printzmetal syndrome

- unstable coronary artery disease

- $\quad$ valve disorders: aortic valve stenosis and mitral valve stenosis

- $\quad$ diseases of the myocardium or the mitral apparatus

- $\quad$ arrhythmia at a rate higher than 100 strokes per minute

- $\quad$ severe forms of exertional angina pectoris and spontaneous angina

- venous blood leaks in the lungs

- $\quad$ acute respiratory diseases of various origin

- $\quad$ effects of drugs, especially antipsychotics and alcohol.

Some relative contraindications also exist concerning participation in the cryogenic treatment. These include the following:

- $\quad$ age above 65

- venous thrombosis and a history of peripheral arterial embolism

- excessive emotional lability, expressed, inter alia, in excessive excitability

Currently whole-body cryostimulation is increasingly popular among older people, also those after 65. The age is not a serious contraindication, if other more important contraindications do not occur [Jagodziński et al. 2001; Zagrobelny 2003; Sieroń et al. 2007].

\section{The effect of cryogenic temperatures on the human body}

Exposure of the human body to cryogenic temperatures results in many favourable physiological phenomena [Jagodzinski et al. 2001; Kiljański et al 2005; Sieroń et al. 2007] such as:

- $\quad$ overall improvement in well-being (relaxation, physical relaxation)

- $\quad$ analgesic effect

- $\quad$ neuromuscular effect (increase of muscle strength)

- profuse flow of blood

- $\quad$ increased systemic immunity

- increase in serum beta endorphins, norepinephrine, adrenaline, testosterone (especially in men)

- $\quad$ antioxidant effect of cryostimulation

The analgesic effect of cryostimulation is the most appreciated by practitioners. Hypothermia is related to a reduction in conduction velocity in sensory fibres and in 
impulsation in slowly conducted $\mathrm{C}$ fibres disabling sensory receptors and their connections with proprioreceptors, $\beta$-endorphin secretion [Leppauloto et al. 2008] and the selection of stimuli reaching the central nervous system ( the "control gate" mechanisms) [Gregorowicz et al. 1998; Sieroń et al. 2003].

Sensory fibres experience slower conduction and blocking of afferent hyperalgesia impulsation to the spinal cord. These mechanisms raise the pain threshold. At the same time, it has been found that response to pain involves almost all the glands of internal secretion, with a special role of endorphins in the chain of endocrine responses to pain [Suszko 2003].

The impact on the psyche is a very positive effect of cryostimulation. Through the activity of the central nervous system, patients who underwent cryostimulation sessions in a cryochamber, felt lower fatigue and a radical improvement in mood. Other observed effects include elimination of clinical depression syndromes, easier sleep and improvements in sleep quality [Zagrobelny \& Zimmer 1999; Rymaszewska et al. 2007; Sieroń et al. 2007].

Exposure to extremely low temperatures also reduces the intensity of nerve conduction and reduces the reactivity of peripheral sensory-motor endings, which in turn reduces muscle tension. Cryogenic temperatures increase muscle power through the favourable release of motor impulses in the fibres and increased number of motor units involved in work in different muscle groups.

Here are present the main directions of research and their results in terms of the effects of whole-body cryostimulation on the body.

\section{Motor activities and physical efficiency}

Research by Łuczak, carried out on a large group of athletes (300 people), was meant to find an optimal operating temperature during the whole-body cryostimulation for the improvement of motor skills. The effects of exposure were compared between two 10 minute whole-body cryostimulations $\left(\right.$ at $-100^{\circ} \mathrm{C},-130^{\circ} \mathrm{C}$ and $-160^{\circ} \mathrm{C}$ ) and physical efficiency, based on an assessment of agility, balance, speed and dynamic strength of abdominal muscles. The analysis of the results showed no effect of cryostimulation on the level of agility. Balance improved significantly in groups exposed to temperatures below $-100^{\circ} \mathrm{C}$, while no significant effects were observed for $-100^{\circ} \mathrm{C}$. Parameters evaluating speed and dynamic strength of abdominal muscles improved most after the application of $-100^{\circ} \mathrm{C}$. It was proposed that whole body cryotherapy exerts positive effects on human motor characteristics, although the lowest cryogenic temperatures should be used in only specific cases [Łuczak et al. 2006]. Subsequent studies showed that a series of 20 stimulations with an average temperature $-130^{\circ} \mathrm{C}$ performed on martial arts competitors, resulted in an extended duration of exercise and lower subjective feeling of fatigue at increasing mean speed and angle of treadmill inclination during an exercise according to the Bruce protocol [Hagner et al. 2009]. A recent study on the effects of whole-body cryostimulation on aerobic and anaerobic capacities showed that three 10 minute sessions (average temperature $-130^{\circ} \mathrm{C}$ ) increased maximal anaerobic power in males but not in females, and did not influence aerobic capacity in either gender [Klimek et al. 2011]. There are also reports of improved exercise tolerance, expressed by a lower level of lactates, heart rate and increased threshold capacity during a rowing ergometer test by Olympic team athletes (rowers) after 23 
cryostimulation sessions (3-minutes at a temperature of $-150^{\circ} \mathrm{C}, 2 \times$ day) [ChwalbińskaMoneta 2003].

\section{Cardiovascular response}

It is known that cold exposure is a risk factor for hypertension. In physiotherapeutic practice, it is standard procedure to test participants before cryostimulation where a blood pressure control is measured, but contraindications to the use of cryotherapy or whole-body cryostimulation do not include unstable blood pressure or hypertension. Literature data on changes in key cardiovascular indicators in humans exposed to cryogenic temperatures are ambiguous. Some of them report a significant but short-term increase in systolic and diastolic blood pressure after WBC in both normotensive and mildly hypertensive individuals [Westerlund et al. 2004; Fricke 1989; Taghawinejad et al. 1989]. Similarly, Komulainen et al. [2004] observed a rapid increase in blood pressure in mildly hypertensive subjects exposed to $-15^{\circ} \mathrm{C}$. Other authors reported that thermal stress $\left(-110^{\circ} \mathrm{C}\right)$ did not cause changes in systolic or diastolic blood pressure but only a decrease in the heart rate [Zalewski 2009].

In our experiments we observed no changes in blood pressure or heart rate influenced by the potential stress resulting from the planned participation in cryostimulation. However, we observed a statistically significant increase in systolic $(\mathrm{p} \leq 0.001)$ and diastolic $(\mathrm{p} \leq 0.05)$ blood pressure immediately after a 3 minute long whole-body cryostimulation. These changes did not last more than 10 minutes after the cryostimulation when the values returned to initial levels [Lubkowska \& Suska 2011]. In another study, in which we used 15 daily cryostimulations $\left(-130^{\circ} \mathrm{C} / 3 \mathrm{~min}\right)$, the average increases in SBP and DBP on the first day were $20 \mathrm{mmHg}$ and $6 \mathrm{mmHg}$. All the observed changes in the circulatory system subsided after 10 minutes of resting in a sitting position. Changes in blood pressure were accompanied by a decrease in heart rate by $8 \pm 4 \mathrm{bpm}$. The mentioned changes were not different on the 1st, 5th, 10th and 15th days of the experiment and it can therefore be argued that no adaptation changes occurred in response to the repeated stress associated with the cold [Lubkowska \& Szyguła2010].

\section{Lipid profiles}

There are only a few reports in literature on the influence of whole-body cryostimulation on lipid levels in blood serum. The first information comes from experimental animal models [Skrzep-Poloczek et al. 2002]. Our last report concerned the results of lipid profiles in response to different procedures of whole-body cryostimulation in a cryochamber $\left(-130{ }^{\circ} \mathrm{C}\right)$ for five, ten and twenty sessions. We ascertained that five sessions of whole-body cryostimulation in a cryogenic chamber did not change the lipid profile; while in a group subjected to a series of 10 sessions, the level of TG values statistically significantly decreased, and the changes were more pronounced in the group subjected to 20 sessions: a significant reduction in LDL, reduction in total cholesterol, while a significant increase was observed for HDL fraction. Comparing the ratios of individual lipid fractions, a statistically significant decrease in the TG fraction was observed in relation to total cholesterol, while the HDL fraction increased in comparison with total cholesterol and LDL cholesterol after 20 cryostimulations. No changes in the proportions between lipid fractions were observed after 5 and 10 cryostimulations [Lubkowska et al. 2010] 


\section{Hematology}

Literature on changes in haematological indices induced by cryostimulation are often inconsistent and insufficient. Blatteis [1998] reported a decrease in leukocytes and erythrocytes in healthy subjects after a series of cryostimulations. No significant increase in leukocytes was reported by Stanek et al. [2006], although they also observed a significantly increased percentage of monocytes in healthy individuals after a series of 10 two-minute long cryostimulations at $-120^{\circ} \mathrm{C}$. Similarly, in our studies the increase concerned the number of lymphocytes and monocytes, and to a lesser extent, neutrophils and eosinophiles [Lubkowska et al. 2009]. With regards to information on the effect of cryotherapy or cryostimulation on the red blood cell system, data is still very scarce. The only available paper is Banfi et al. [2008] which investigated the effects of 5 session of whole-body cryotherapy treatment on haematological values in athletes. The paper suggested that cryotherapy does not have detrimental effects on the mentioned parameters, but a small significant decrease in haemoglobin concentration, mean corpuscular haemoglobin and mean reticulocyte volume were observed.

In terms of the participation of white and red blood cells in effort ability and tolerance, further studies are required on potential changes in haematological indices in response to varied number of cryostimulation in a series.

\section{Hormones}

A single cryostimulation at $-130^{\circ} \mathrm{C}$ causes increased concentration of a proopiomelanocortinrelated hormone (ACTH adrenocorticotropic hormone), $\beta$-endorphin, adrenaline and noradrenaline in men and women, and a significant increase in testosterone in men [Zagrobelny 1993]. Soccer players undertaking ten sessions of cryostimulation followed by 60 minutes of kinesitherapy, had a significant decrease in the concentration of testosterone and estradiol. There were no changes in the level of luteinizing hormone (LH) and dehydroepiandrosterone sulphate [Korzonek-Szlacheta 2007]. Reports of changes in the level of cortisol (defined as the stress hormone) are divergent. Smolander et al.[2009] concluded that $\mathrm{WBC}$ treatments $\left(-110^{\circ} \mathrm{C}\right)$, for $2 \mathrm{~min}$, three times a week for 12 weeks, do not lead to disorders related to secretions of the growth hormone, prolactin, thyrotropin or thyroid hormones in healthy females.

Literature data indicate that in elderly women, cryotherapy at temperatures of $-110^{\circ} \mathrm{C}$ to $150^{\circ} \mathrm{C}$ influence the level of bone conversion markers (a decline in osteocalcin, increased alpha type I collagen in blood serum) [Skrzek et al. 2003], and that rheumatoid arthritis patients were reported to have a decreased histamine level [Wojtecka-Łukasik et al. 2010].

\section{Antioxidant defence system}

Even one session of whole-body cryostimulation causes changes in the prooxidantantioxidant balance - the level of total oxidative status in plasma was statistically significantly decreased at 30 minutes after leaving the cryochamber and remained lower the following day, whereas the level of total antioxidative status decreased after cold exposure and increased the next day [Lubkowska et al. 2008]. Additionally, a 36\% increase was observed in the activity of superoxide dismutase (SOD), glutathione peroxidase (GPx) and conjugated dienes (CD) in healthy individuals after a single stimulation [Woźniak et al. 2007]. Duge et al. [2005] observed a significant increase in total peroxyl radical trapping 
antioxidant capacity of plasma (TRAP) in healthy women 2 minutes after the cold stress but only after the first 4 weeks of the 12 weekend long study. Additionally those authors concluded that prolonged, regular cryostimulation or winter swimming for 12 weeks did not appear to be harmful regarding antioxidative capacity. Further studies are needed for the confirmation of potential adaptational advantages occurring in antioxidative response to cryostimulation.

\section{Immunology and inflammation}

Cryotherapy is used in the early treatment of acute injuries (sprains, strains, fractures) but only a few papers discuss any possible influence of whole-body cryostimulation on inflammation mechanisms or immunology. In studies by Jackowska et al. [2006] it was ascertained that IgA, IgG, IgM and C3, C4 complement protein levels increase during cryostimulation, yet after cryotreatment, the levels of the mentioned markers were similar to initial values. Leppäluoto et al. [2008] did not observe changes in plasma level of IL-1 $\beta$, Il-6 and TNFa during prolonged treatment (12 weeks) with cryostimulation $\left(-110^{\circ} \mathrm{C} ; 2 \mathrm{~min} ; 3\right.$ times a week). In our studies, we observed an increase in the level of white blood cells in response to a series of 10 cryostimulations, and at the same time we showed that a single 3 minute long whole-body cryostimulation $\left(-130^{\circ} \mathrm{C}\right)$ leads to an increase in the level of interleukin 6, which is maintained for the next 10 stimulations [Lubkowska et al 2010 ]. This was later confirmed in the next experiment, which additionally showed the more advantageous effect of 20 sessions compared to 10 or 5 cryostimulations. This advantageous effect - an increased level of anti-inflammatory cytokines (IL-6, IL-10, IL-12) - was maintained during the whole series of cryostimulations, and receded no earlier than after two weeks after the completion of the cryostimulations, regardless of the number of treatments. However, although the decreased level of pro-inflammatory IL-1a was observed during the series of 5 and 10 treatment, in an examination two weeks after the last stimulation the IL-1a decrease was maintained only after the series of 20 cryostimulation treatments [Lubkowska et al. 2011].

The anti-inflammatory effect of cryotreatment on rugby players lead to an increase in antiinflammatory cytokinase IL-10 with a decrease in pro-inflammatory IL-2 and chemokine IL8. It was postulated that cold exposure had an immunostimulating effect related to enhanced noradrenaline response and can be connected with paracrine effects. Similar tendencies in decrease in pro-inflammatory cytokine (IL-2, Il-8) and increase in antiinflammatory one (IL-10) after cryostimulation were observed by Banfi et al. [2009].

\section{Recovery from exercise-induced muscle damage}

Some of the latest papers on cryotherapy relate to the use of cryostimulation in athletic recovery, acceleration of recovery to full physical ability, and removing the results of muscle fibre damage caused by intense exercise. It is promoted as a treatment method for muscle injuries, syndromes of overuse and to enhance recovery between training sessions [Banfi et al. 2010].

Difficulty with the evaluation of the advantageous effect of cryostimulation is associated, as in earlier aspects, with the very small number of papers in this field. Costello et al. [2011] performed very interesting studies to evaluate the immediate effect of cryostimulation on proprioception and tried to evaluated the effectiveness of this treatment in muscle soreness and function following eccentric exercise damage. Based on obtained results, the authors 
suggest that although cryostimulation does not increase the risk of proprioceptive related injury, it is ineffective in improving recovery if administered $24 \mathrm{~h}$ after exercise. In another study [Pournot et al. 2011] researchers compared the effect of two different recovery modalities: cryostimulation $\left(3 \mathrm{~min}\right.$ at $-110^{\circ} \mathrm{C}$ ) and passive recovery, on markers of exerciseinduced muscle damage and inflammation obtained after a simulated trail running race. The recovery session was applied immediately after, $24 \mathrm{~h}, 48 \mathrm{~h}$ and $72 \mathrm{~h}$ after subjects performed a $48 \mathrm{~min}$ running treadmill exercise. The author observed that a unique session of cryostimulation performed immediately after exercise enhanced muscular recovery by restricting the inflammatory process. They suggested that soluble receptor antagonist IL-1ra increases after single whole-body cryostimulation and restricts the inflammatory response to exercise by a decrease in the magnitude if IL-1 $\beta$ and protein C-reactive. This research indicates that this physiotherapeutic treatment reduces the time of recovery, although depending on the time lag from the intense effort to cryostimulation. Further studies are required for a detailed understanding of mechanisms of response to cryogenic temperatures to find their most effective application in athletic training and recovery.

\section{Conclusions}

Whole-body cryostimulation is a factor that can influence many physiological and biochemical indicators in the human body. Triggering physiological defensive mechanisms in response to a repeated external stressor (cold) may be widely used in medicine, physiotherapy, sport and athlete recovery. However, it is important to select an appropriate duration, form and number of cryostimulations, according to the needs of each patient.

The aforementioned literature data very often relates to different procedures and methodologies. Hence the results are often inconsistent and do not always give a clear view of the discussed problem. It is hard to conclude on the real effectiveness of cryostimulation when it is accompanied by daily physical training which is in itself a stressogenic factor for the human body. In order to achieve a precisely determined effect of cryostimulation on athletes or patients, one should use appropriate methods. In addition, there exists the problem of immersion in cold water which is accompanied by another stressor - i.e. hydrostatic pressure, depending on the depth of immersion.

There exists no single agreed recommendation concerning the number of cryostimulations in a series. Usually, 10 daily sessions are applied, although this is less related to therapeutic reasons than economic ones. It is also not widely agreed how many cryostimulations give real and sustained beneficial effects and whether the adaptive changes in subjects depend on the number of sessions, although this correlation seems very likely.

Because the interest in using cold temperatures in medicine, physiotherapy, sport and athlete recovery is constantly growing, and knowledge in this field is still far from satisfactory, any new research on the use of cryogenic temperatures is a welcome and precious source of information from the point of view of physiotherapeutic practice.

\section{References}

Adamowicz, B. (2005). Cryogenic chambers - a matter of choice. Acta Bio - Optica et Informatica Medica Vol. 11, No. 1-2, pp. 44-46 
Banfi, G.; Lombardi, G.; Colombini A. \& Melegati G. (2010). Whole-Body Cryotherapy in Athletes. Sports Medicine, Vol. 40, No. 6, pp. 509-517

Banfi, G.; Krajewska, M.; Melegati, G. \& Patacchini, M. (2008). Effects of whole-body cryotherapy on haematological values in athletes. British Journal of Sports Medicine, No. 42, pp. 558-559

Banfi, G.; Melegati, G.; Barassi, A.; Dogliotti G.; d'Eril, G.M.; Dugué B. \& Corsi M.M. (2009). Effects of whole-body Cryotherapy on serum mediators of inflammation and serum muscle enzymes in athletes. Journal of Thermal Biology, Vol. 34, No. 2, pp. 5559

Biały, D.; Zimmer, K. \& Zagrobelny, Z. (1998). Cryochamber - advantages of its use in rehabilitation - own experiences. Adamowicz, B. (2005). Cryogenic chambers - a matter of choice. Acta Bio - Optica et Informatica Medica, Vol. 4, No.4, pp. 169-172

Bieńkowska, A.; Molski, P.; Dzierżanowski, M.; Bułatowicz, I. \& Hagner W. (2006). Pain and cryotherapy in the treatment of complex medical treatment of the human motor system. Kwartalnik Ortopedyczny, No. 4, pp. 311 - 314

Blatteis, C.M. (1998). Physiology and pathophysiology of temperature regulation. World Scientific Co. Pte. Ltd. ISBN 981-02-3172-5

Boerner, E.; Brzyk, R. \& Bienias - Jędrzejewska, M. (2007). Evaluation of the effectiveness of local cryotherapy in treating the shoulder impingement syndrome. Acta Bio - Optica et Informatica Medica, Vol. 13, No 1, pp. 54 - 56

Bojek, W. (2006). Cryotherapy - general comments. Balneologia Polska No. 1,pp. 64 - 67

Brojek ,W. \& Warzocha, A. (2006). Cryochamber - most frequently asked questions.(Part II). Acta Bio -Optica et Informatica Medica, Vol. 12, No.2, pp. 205-206

Cholewka, A. \& Drzazga, Z. (2005). Whole-body cryotherapy in a two-stage cryochamber and in a cryobarrel . Acta Bio - Optica et Informatica Medica, Vol. 11, No 1-2, pp. 49-54

Chwalbińska-Moneta J. (2003). Influence of whole-body cryotherapy of results of selected exercise response. Sport Wyczynowy, No. 5-6, pp. 461-462

Different amount of sessions in healthy men. Scandinavian Journal of Clinical \& Laboratory Investigation, Vol. 71, No. 5, pp. 419-425

Dugué, B.; Smolander, J.; Westerlund, T.; Oksa, J.; Nieminen, R.; Moilanen, E. \& Mikkelsson, M. (2005). Acute and long-term effects of winter swimming and whole-body cryotherapy on plasma antioxidative capacity in healthy women. Scandinavian Journal of Clinical \& Laboratory Investigation Vol. 65, No. 5, pp. 395-402

Fricke R. (1989). Ganzkoperkaltetherapie in einer Kaltekammer mit Temperaturen $-110^{\circ} \mathrm{C} . \mathrm{Z}$ Phys Med Baln Med Klim No. 18, pp. 1-10

Gregorowicz, H. \& Zagrobelny, Z. (1998). Cryotherapy in Multiple Sclerosis treatment. Acta Bio - Optica et Informatica Medica, Vol. , No. 4, pp. 173-174.

Hagner, W.; Smolka, A. \& Różańska J. (2009). Influence of whole-body cryotherapy of results of exercise test. Balneologia Polska, Vol.115, No.1, pp. 35-39

Hopkins, J.T. (2006). Knee Joint Effusion and Cryotherapy Alter Lower Chain Kinetics and Muscle Activity. Journal of Athletic Training; Vol.41, No.2, pp. 177-184

Jackowska, E.; Pisula, A.; Drulis-Kawa, Z.; Guz, K.; Bugla-Płoskońska, G.; Doroszkiewicz, W. \& Stręk, W. (2006). Changes of level of immunoglobulins and C3 and C4 proteins in serum during whole-body cryotherapy. Acta bio-Optica et Informatica Medica, Vo. 12, No.2, pp. 101-103 
Jagodziński, L.; Kubacka, M.; Wiśniowska, B.; Puszer, M. \& Stanek A. (2001). Whole-body cryostimulation. Part II. Gabinet Prywatny, Vol. 92, No. 4, pp. $10-11$

Jezierski C.: Cryostimulation in rheumatology, traumatology, orthopedics and rehabilitation (partII. Acta Bio - Optica et Informatica Medica, Vol. 4, No. 13, pp. 336 - 337

Jezierski, C. (2006). Methodology and principles of local cryostimulation techniques. Acta Bio - Optica et Informatica Medica, Vol. 3, No.12, pp.200 - 201

Jezierski, C. (2007). Cryostimulation in rheumatology, traumatology, orthopedics and rehabilitation treatments (part I). Acta Bio - Optica et Informatica Medica, Vol. 3, No. 13, pp. 240 - 242

Kasprzak, W. \& Markowska, A. (2008). Physiotherapy. PZWL Wydawnictwo Lekarskie, Warsaw 2008, pp. 18 - 22

Kiljański, M.; Clayton, M.; Karpiński, J.; Szczepaniak, R.; Kiebzak, W. \& Kałuża, J (2005). Evaluation of an individual cryochamber in a comprehensive physiotherapy based on own observation. Fizjoterapia Polska, Vol. 5, No. 2, pp. $207-210$

Klimek, A.T.; Lubkowska, A.; Szygula, Z.; Chudecka, M. \& Frączek B. (2010). The influence of the ten sessions of the whole body cryostimulation on aerobic and anaerobic capacity. International Journal of Occupational and Environmental Health, Vol. 23, No. 2, pp. 181-189, ISSN: 1896-494X

Klimek, A.T; Lubkowska, A.; Szyguła, Z.; Frączek, B. \& Chudecka M. (2011). The influence of single whole body cryostimulation treatment on the dynamics and the level of maximal anaerobic power. International Journal of Occupational and Environmental Health, Vol.24, No.2, pp. 184 - 191, ISSN: 1896-494X

Komulainen, S.; Oja, T.; Rintamaki, H.; Virokannas, H. \& Keinanen - Kiukaanniemi, S. (2004). Blood pressure and thermal responses to whole body cold exposure in mildly hypertensive subjects. Journal of Thermal Biology, Vol. 29 , No. 7-8, pp. 851856

Korzonek-Szlacheta, L.; Wielkoszyński, T.; Stanek A.; Świętochowska, E.; Karpe, J. \& Sieroń, A. (2007). Influence of whole-body cryotherapy on the levels of some hormones in Professional footballers. Polish Journal of Endocrinology, Vol.58, No. 1, pp. 27-32

Krawczyk - Wasilewska, A.; Kuncewicz, E.; Sobieska, M. \& Samborski, W. (2007). Evaluation of the effectiveness of physical therapy in relieving pain accompanying rheumatoid arthritis. Nowa Medycyna, No. 4, pp. 74 - 79

Księżopolska - Pietrzak, K. (1998). Cryotherapy in osteoporosis. Polski Merkuriusz Lekarski, Vol. 28 No.5, pp. 222 - 224, ISSN: 1426-9686

Leppäluoto, J.; Westerlund, T.; Huttunen, P.; Oksa, J.; Smolander, J.; Dugué, B. \& Mikkelsson, M. (2008). Effects of long-term whole-body cold exposures on plasma concentrations of ACTH, beta-endorphin, cortisol, catecholamines and cytokines in healthy females. Scandinavian Journal of Clinical \& Laboratory Investigation, Vol. 68, Nzo.2, pp. 145-153, ISSN: 0036-5513

Lisinski, P.; Jozwiak, D. \& Samborski, W. (2005). Cold therapy and cryotherapy in treating patients with pains in the area of the shoulder joint. Chirurgia Narzadów Ruchu $i$ Ortopedia Polska, Vol. 70, No. 6, pp. 435 - 438

Lubkowska, A.; Dolegowska, B.; Szygula, Z. \& Klimek, A.T. (2009). The activity of selected enzymes in erythrocytes and the level of plasma antioxidants in response to single whole-body cryostimulation in humans. Scandinavian Journal of Clinical $\mathcal{E}$ Laboratory Investigation, Vol. 69, No. 3, pp. 387 -394 
Lubkowska, A. \& Suska, M. (2011). The increase in systolic and diastolic blood pressure after exposure to cryogenic temperatures in normotensive men as a contraindication for whole-body cryostimulation. Journal of Thermal Biology, Vol. 36, No. 5, pp. 264-268

Lubkowska, A. \& Szygula Z. (2010). Changes in blood pressure with compensatory heart rate decrease and level of aerobic capacity in response to repeated whole-body cryostimulation in normotensive, young and physically active men. International Journal of Occupational and Environmental Health, Vol. 23, No. 4, pp. 367-375, ISSN: 1896-494X

Lubkowska, A.; Chudecka, M.; Klimek, A.T.; Szyguła, Z. \& Frączek B. (2008). Acute effect of a single whole-body cryostimulation on prooxidant-antioxidant balance in blood of healthy young men. Journal of Thermal Biology, Vol. 33, No.8, pp. 464-467

Lubkowska, A.; Banfi, G.; Dołęgowska, B.; d'Eril, G.M.; Łuczak, J. \& Barassi, A. (2010). Changes in lipid profile in response to three different protocols of whole-body cryostimulation treatments. Cryobiology, No. 61, pp. 22-26, ISSN 0011-2240

Lubkowska, A.; Szyguła, Z.; Chlubek, D. \& Banfi, G. (2011). Serum mediators of inflammation level: IL-1 $\alpha$, IL-1 $\beta$, IL-6, IL-10, IL-12 and TNFa during prolonged whole-body cryostimulation treatment with different amount of sessions in healthy men. Scandinavian Journal of Clinical \& Laboratory Investigation, Vol. 71, No.5, pp. 419-25

Lubkowska, A.; Szyguła, Z.; Klimek, A. \& Torii, M. (2009). Do sessions of cryostimulation have influence on white blood cells count, level of IL6 and the total oxidative and antioxidative status in healthy men. European Journal of Applied Physiology, Vol. 109, No. 1, pp.67-72

Łuczak, J. \& Michalik, J. (2006). Wpływ skrajnie niskich temperatur na wybrane cechy motoryczne człowieka. Fizjoterapia Polska, Vol. 3, No. 4, pp. 206-211.

Migaj, R. (2005). Treatment with cold generated by the compressor cooling system. Acta Bio Optica et Informatica Medica, Vol. 11, No. 1-2, pp. 55

Pasek, J.; Pasek , T. \& Sieroń, A. (2009). Local and systemic cryotherapy in patients with degenerative arthritis. Rehabilitacja w Praktyce, No. 2, pp. 32 - 33

Pournot, H.; Bieuzen, F.; Louis, J.; Fillard, J.R.; Barbiche, E. \& Hausswirth, C. (2011). TimeCourse of Changes in Inflammatory Response after Whole-Body Cryotherapy Multi Exposures following Severe Exercise. PLoS ONE, Vol.6, No. 7,e22748. Doi:10.1371/journal.pone.0022748

Raczkowski, J. \& Daniszewska, B. (2007). Cryotherapy - use of extremely low temperatures in medical treatment. Acta Bio - Optica et Informatica Medica, Vol. 13, No.1, pp. 58 60

Rawecka, D. \& Rokita E. (2006). Local cryotherapy - has everything been said? Acta Bio Optica Informatica Medica, Vol. 2, No.12, pp. 111-115

Rymaszewska, J.; Ramsey ,D.; Chładzińska-Kiejna, S. \& Kiejna, A. Can short-term exposure to extremely low temperatures can be helpful in the treatment of depressive disorders and fears? Psychiatria Polska, Vol. 41, No. 5, pp. 625-636, ISSN: 0033-2674

Sieron, A. \& Cieslar, G. (2003). Cryotherapy - treatment with cold. a - medica Press 2003, ISBN 83-88778 59-5

Sieroń, A.; Stanek, A.; Cieślar, G. \& Pasek, J. (2007). Cryorehabilitation - Role of cryotherapy in the contemporary rehabilitation. Fizjoterapia, Vol. 15, No. 2, pp. 3 - 8 
Skrzek A. (2009). The history of whole-body cryotherapy in Poland. Acta Bio - Optica et Informatica Medica, Vol. 4, No.15, pp.309-313

Skrzek, A.; Bolanowski, M.; Zagrobelny, Z. \& Lubczyńska-Kowalska, W. (2003). The influence of whole body cryotherapy followed by relaxing gymnastics on bone turnover and muscular function in elderly women. Acta Bio - Optica et Informatica Medica, Vol. 9, No. 1-2, pp. 45-51

Skrzep-Poloczek, B.; Romuk, E. \& Birkner, E. (2002). The effect of whole-body cryotherapy on lipids parameters in experimental rat model. Balneologia Polska 2002; No. 1-4, pp. 7-13

Smolander, J.; Leppäluoto, J.; Westerlund, T.; Oksa, J.; Dugue, B.; Mikkelsson, M. \& Ruokonen, A. (2009). Effects of repeated whole-body cold exposures on serum concentrations of growth hormone, thyrotropin, prolactin amd thyroid hormones in healthy women. Cryobiology, Vol. 58, No. 3, pp. 275-278

Stanek, A.; Cieslar, G.; Rosmus-Kuczia, I, Matyszkiewicz, B.; Romuk, E.; Skrzep-Poloczek, B.; Birkner, E. \& Sieron A. (2006). Influence of whole body cryotherapy on blood morphology parameters in patients with ankylosing spondylitis and in healthy volunteers. Acta Bio - Optica et Informatica Medica, Vol. 12, No. 3, pp. 207-210

Straburzyńska - Lupa, A.; Czubaszewski, L.; Romanowski, W. \& Świetlik, Z. (2005). Comparative studies of single treatment with cold air and liquid nitrogen vapour in patients with rheumatoid arthritis. Fizjoterapia Polska, Vol. 3, No. 5, pp. 323 - 328

Suszko, R. (2003). Whole-body cryotherapy. Rehabilitacja Medyczna , Vol. 7, No. 2, pp. 63- 71

Suszko, R. (2003). Whole-body cryotherapy. Rehabilitacja Medyczna Vol. 7, No. 2, pp. 63, 65 71

Taghawinejad, M.; Birwe, G.; Fricke, R. \& Hartman, R. (1989). Ganzkoperkaltetherapie Beeinflussung von Kreislauf - un Stoffwechselparametern. Z Phys Med Baln Med Klim, No. 18, pp. 23-30

Westerlund, T.; Smolander, J.; Uusitalo-Koskinen, A. \& Mikkelsson, M. (2004). The blood pressure responses to an acute and long-term whole-body cryotherapy $\left(-110^{\circ} \mathrm{C}\right)$ in men and women. Journal of Thermal Biology Vol. 29, No 6, pp. 285-290, ISSN: 03064565

Westerlund, T.; Smolander, J.; Uusitalo-Koskinen, A. \& Mikkelsson M. (2004). The blood pressure responses to an acute and long-term whole-body cryotherapy $\left(-110^{\circ} \mathrm{C}\right)$ in men and women. Journal of Thermal Biology, Vol. 29, No. 6, pp. 285-290.

Wojtecka-Łukasik, K.; Księżopolska-Orłowska, E.; Gaszewska, O.;, Krasowicz-Towalska, P.; Rzodkiewicz-Maślińska, D.; Szukiewicz, S. \& Maśliński, E. Cryotherapy decreases histamine levels in the blood of patients with rheumatoid arthritis. Inflammatory Research, Vol. 59, No. 2, pp. 253-255

Woźniak, A.; Woźniak, B; Drewa, G.; Mila-Kierzenkowska, C. \& Rakowski, A. (2007). The effect of whole-body cryostimulation on the prooxidant-antioxidant balance in blood of elite kayakers after training. European Journal of Applied Physiology, Vol. 101, pp. 533-537

Woźny A., Kujawa J., Pieszyński I., Gworys K. \& Puzder A. (2006). Evaluation of the analgesic effectiveness of McKenzie physiotherapy method in combination with local cryotherapy in patients with lumbosacral pain syndromes. Kwartalnik Ortopedyczny, No. 1, pp. $63-69$ 
Zagrobelny Z. \& Zimmer, K. (1999). The use of cryogenic temperatures in sports medicine and physiotherapy. Rehabilitacja Medyczna, Vol. 94, No. 15, pp. 8 - 13

Zagrobelny Z. \& Zimmer, K. (1999). The use of cryogenic temperatures in medicine and sport physiotherapy. Medycyna Sportowa Vol.94,No. 5,pp. 8 - 13

Zagrobelny, Z. (2003). Local and whole-body cryotherapy. Elsevier Urban \& Partner; Wrocław 2003

Zalewski, P.; Tafil-Klawe, M.; Klawe, J.; Buszko, K.; Lewandowski, A. \& Panowicz, I. (2009). Influence of the whole-body cryotherapy on the hemodynamic parameters in healthy subjects. Acta Bio - Optica et Informatica Medica, Vol.15, No. 3, pp.209-214 


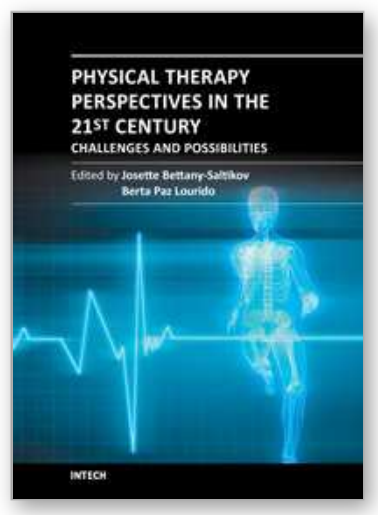

\section{Physical Therapy Perspectives in the 21st Century - Challenges and Possibilities}

Edited by Dr. Josette Bettany-Saltikov

ISBN 978-953-51-0459-9

Hard cover, 386 pages

Publisher InTech

Published online 05, April, 2012

Published in print edition April, 2012

This book contains new information on physical therapy research and clinical approaches that are being undertaken into numerous medical conditions; biomechanical and musculoskeletal conditions as well as the effects of psychological factors, body awareness and relaxation techniques; specific and specialist exercises for the treatment of scoliosis and spinal deformities in infants and adolescents; new thermal agents are being introduced and different types of physical therapy interventions are being introduced for the elderly both in the home and clinical setting. Additionally research into physical therapy interventions for patients with respiratory, cardiovascular disorders and stroke is being undertaken and new concepts of wheelchair design are being implemented.

\section{How to reference}

In order to correctly reference this scholarly work, feel free to copy and paste the following:

Anna Lubkowska (2012). Cryotherapy: Physiological Considerations and Applications to Physical Therapy, Physical Therapy Perspectives in the 21st Century - Challenges and Possibilities, Dr. Josette Bettany-Saltikov (Ed.), ISBN: 978-953-51-0459-9, InTech, Available from: http://www.intechopen.com/books/physical-therapyperspectives-in-the-21st-century-challenges-and-possibilities/cryotherapy-physiological-considerations-andapplications-to-physical-therapy

\section{INTECH}

open science | open minds

\author{
InTech Europe \\ University Campus STeP Ri \\ Slavka Krautzeka 83/A \\ 51000 Rijeka, Croatia \\ Phone: +385 (51) 770447 \\ Fax: +385 (51) 686166 \\ www.intechopen.com
}

\author{
InTech China \\ Unit 405, Office Block, Hotel Equatorial Shanghai \\ No.65, Yan An Road (West), Shanghai, 200040, China \\ 中国上海市延安西路65号上海国际贵都大饭店办公楼 405 单元 \\ Phone: +86-21-62489820 \\ Fax: +86-21-62489821
}


(C) 2012 The Author(s). Licensee IntechOpen. This is an open access article distributed under the terms of the Creative Commons Attribution 3.0 License, which permits unrestricted use, distribution, and reproduction in any medium, provided the original work is properly cited. 